Supporting Information for

\title{
Analyzing the Role of Surfactants on the \\ Colloidal Stability of Nanoparticles in \\ Oil Through Coarse-Grained Molecular \\ Dynamics Simulations
}

\author{
Mark Z. Griffiths and Wataru Shinoda*
}

Department of Materials Chemistry, Nagoya University, Furo-cho Chikusa-ku, Nagoya 464-8603, Japan

The SPICA Coarse Grained Force Field

The SPICA Force Field $(F F)^{1,2}$ was originally developed for surfactants and lipid membrane systems and designed to recreate experimental and atomistic data through unique and transferable bead parameters. Bond stretching and angle bending interactions are modeled through the harmonic potential;

$$
U_{1,2}=\sum_{\{i, j\}}^{\text {bond }} k_{b}\left(r_{i j}-r_{0}\right)^{2}
$$

for bonds and

$$
U_{1,2,3}=\sum_{\{i, j, k\}}^{\text {angle }} k_{\theta}\left(\theta_{i j k}-\theta_{0}\right)^{2}
$$

for angles. $k_{b}$ and $k_{\theta}$ are the bond and angle force constants, $r_{0}$ and $\theta_{0}$ the equilibrium bond length and angle.

Non-bonded interactions between beads $i$ and $j$ are modeled through the Lennard-Jones potential 


$$
U\left(r_{i j}\right)=\frac{27}{4} \varepsilon_{i j}\left[\left(\frac{\sigma_{i j}}{r_{i j}}\right)^{9}-\left(\frac{\sigma_{i j}}{r_{i j}}\right)^{6}\right]
$$

where $\varepsilon_{i j}$ is the well depth of the potential, $\sigma_{i j}$ is the distance with a potential equal to zero.

\section{Nanoparticle and surfactant CG model}

The model for this study was chosen to make full use of the existing SPICA parameters by choosing species whose constituent bead parameters are already known. Thus, the time-consuming step of parameterization is considerably reduced and simplified. The only unknown parameters requiring tuning are a specialized bead for the surfactant head group and the nanoparticle beads constructing the carbon framework of the nanoparticle. The nanoparticle in the system is designed to be analogous to carbonblack found in car engines because removal of carbon impurities from engines is an important process. Prevention of carbon-black particle aggregation and subsequent growth to precipitate out of the oil is important to engine oil efficiency and life-span, along with protecting the engine integrity and function. Carbon black is a non-uniform aggregation of varying hydrocarbon moieties found within a combustion engine. The spherical structure of a single carbon-black particle consists of offset overlapping graphene like sheets with peripheral polar groups, such as $-\mathrm{COOH},-\mathrm{OH}$, and $-\mathrm{COO}^{-}$. Figure 1 shows the CG representation and mapping scheme of the CG nanoparticle surface 
and a CG carbon-black analogue nanoparticle. The model generalizes the nanoparticle to a single graphene sheet bent into a sphere. The carbon atoms are mapped 4 to 1 for each CG bead from the central carbon with its three adjacent carbons as the "CB" bead. This mapping scheme was chosen to maintain the hexagonal motif of the graphene sheet. The polar groups are represented by the SPICA OA bead $\left(-\mathrm{CH}_{2} \mathrm{OH}\right)$ and distrusted evenly across the surface.

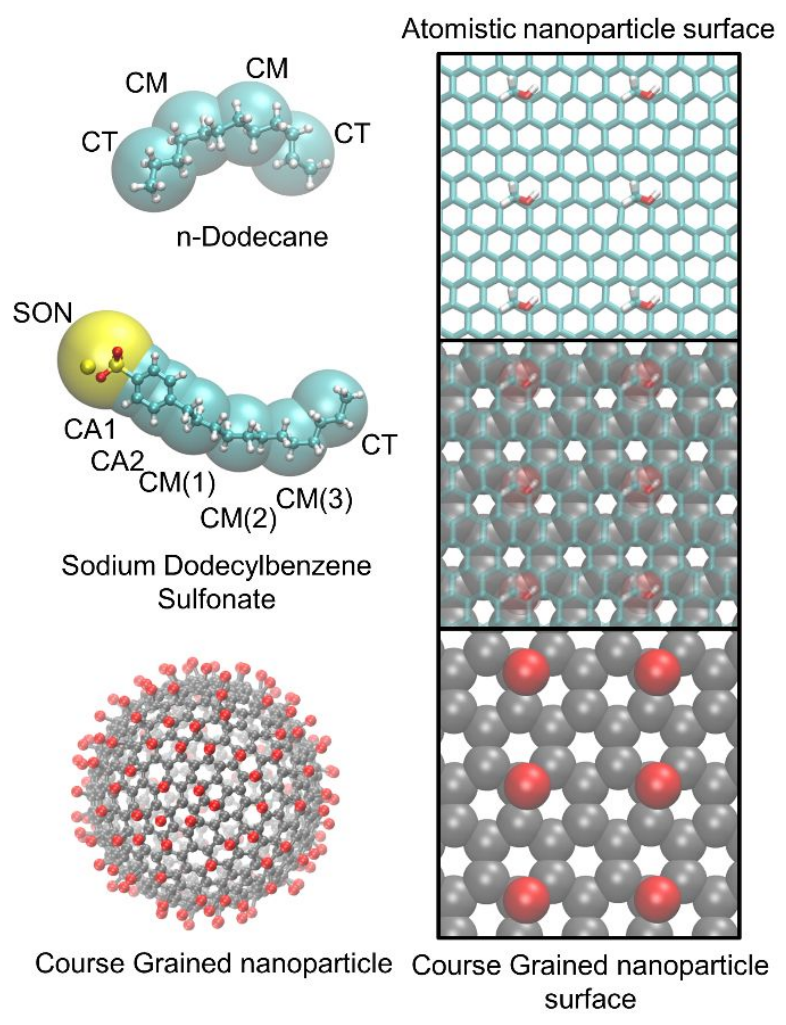

Figure 1: Atomistic to coarse grained mapping scheme for dodecane, surfactant and nanoparticle.

The CB beads of the nanoparticle are treated as a single rigid body mimicking the solid structure of carbon-black, while the $O A$ beads associated to $\mathrm{CB}$ beads are remained flexible. This allows the OA beads to reorientate as the surfactants bind to 
the surface. Parameters for the CB interactions were determined from all atomistic simulations. Two nanoparticle sheets were constructed from reverse mapped CB beads, which create graphene like sheets with bonded polar head groups. Each sheet consisted of 825 carbon atoms arranged as a graphene sheet of dimensions $4.8 \mathrm{~nm} \times 4.2 \mathrm{~nm}$ topological bound across the periodic boundary. $25 \mathrm{CH}_{2} \mathrm{OH}$ (OA bead) groups were evenly distributed across the surface for each sheet. The two sheets were equilibrated with the polar groups facing each other to determine the bound state of the sheets. The sheets were then moved to $4 \mathrm{~nm}$ separation, beyond the non-bonded interaction cutoff. The interaction energy was calculated as the difference between bound and separated states by taking the average energy over $5 \mathrm{~ns}$ for each state. The system was mapped to CG and repeated. The LJ parameters for the interactions were tuned to reproduce the atomistic energy to an error of less than $0.5 \%\left(1.132 \mathrm{kcal} \mathrm{mol}^{-1}\right)$

The surfactant head group parameters were set as weak or strong to represent a range of possible interaction parameters. The strong parameters were determined through QM calculation. The interaction energy between two SDBS molecules with sodium counter ions was determined and the CG LJ parameters tuned to match. The weak parameters were set considerably lower but still higher than any other interaction parameter. If the parameter is not the largest in the system, the head group would no longer 
favor the nanoparticle or other surfactants and the molecule would no longer act as a surfactant. The full parameter set is given in Table 1.

Table 1: Force Field Parameters

\begin{tabular}{|c|c|}
\hline Bead Type & Mass \\
\hline CB & 48.0440 \\
\hline OA & 31.0337 \\
\hline SON & 102.538 \\
\hline CAM & 38.0488 \\
\hline CM & 42.0804 \\
\hline CT & 43.0883 \\
\hline
\end{tabular}

\begin{tabular}{|c|c|c|}
\hline $\mathrm{CB}-\mathrm{CB}$ & 250.0 & 2.880 \\
\hline $\mathrm{CB}-\mathrm{OA}$ & 207.5 & 2.550 \\
\hline $\mathrm{SON}-\mathrm{CAM}$ & 138.5 & 2.522 \\
\hline $\mathrm{CAM}-\mathrm{CAM}$ & 345.0 & 1.910 \\
\hline $\mathrm{CAM}-\mathrm{CM}$ & 9.40 & 2.960 \\
\hline $\mathrm{CM}-\mathrm{CM}$ & 6.16 & 3.640 \\
\hline $\mathrm{CM}-\mathrm{CT}$ & 6.16 & 3.650 \\
\hline
\end{tabular}

\begin{tabular}{|l|l|l|}
\hline Bond Type & $\mathbf{k}_{\mathrm{b}}$ & $\mathbf{r}_{0}$ \\
\hline
\end{tabular}

Angle Type

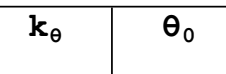




\begin{tabular}{|c|c|c|}
\hline $\mathrm{CB}-\mathrm{CB}-\mathrm{CB}$ & $\begin{array}{c}150 . \\
5\end{array}$ & $\begin{array}{c}118 . \\
0\end{array}$ \\
\hline $\mathrm{CB}-\mathrm{CB}-\mathrm{OA}$ & 25.5 & 90.0 \\
\hline $\begin{array}{c}\mathrm{SON}-\mathrm{CAM}- \\
\mathrm{CAM}\end{array}$ & $\begin{array}{c}101 \\
0\end{array}$ & $\begin{array}{c}177 . \\
6\end{array}$ \\
\hline $\mathrm{CAM}-\mathrm{CAM}-\mathrm{CM}$ & 20.9 & $\begin{array}{c}161 . \\
4\end{array}$ \\
\hline $\mathrm{CAM}-\mathrm{CM}-\mathrm{CM}$ & 2.70 & $\begin{array}{c}157 . \\
6\end{array}$ \\
\hline $\mathrm{CM}-\mathrm{CM}-\mathrm{CM}$ & 1.19 & $\begin{array}{c}173 . \\
0\end{array}$ \\
\hline $\mathrm{CM}-\mathrm{CM}-\mathrm{CT}$ & 1.19 & $\begin{array}{c}175 . \\
0\end{array}$ \\
\hline $\begin{array}{c}\text { Non-Bonded } \\
\text { Pair }\end{array}$ & $\boldsymbol{\varepsilon}$ & $\sigma$ \\
\hline $\mathrm{CB} \quad \mathrm{CB}$ & $\begin{array}{c}0.534 \\
0\end{array}$ & $\begin{array}{c}4.150 \\
0\end{array}$ \\
\hline $\mathrm{CB} \quad \mathrm{OA}$ & $\begin{array}{c}0.365 \\
0\end{array}$ & 4.000 \\
\hline CB $\quad \mathrm{SON}$ & $\begin{array}{c}0.256 \\
5\end{array}$ & $\begin{array}{c}4.175 \\
0\end{array}$ \\
\hline CB $\quad$ CAM & $\begin{array}{c}0.425 \\
0\end{array}$ & $\begin{array}{c}4.475 \\
0\end{array}$ \\
\hline $\mathrm{CB} \quad \mathrm{CM}$ & $\begin{array}{c}0.443 \\
7\end{array}$ & $\begin{array}{c}4.403 \\
0\end{array}$ \\
\hline $\mathrm{CB} \quad \mathrm{CT}$ & $\begin{array}{c}0.458 \\
2\end{array}$ & $\begin{array}{c}4.442 \\
5\end{array}$ \\
\hline$O A \quad O A$ & $\begin{array}{c}0.449 \\
1\end{array}$ & $\begin{array}{c}3.713 \\
0\end{array}$ \\
\hline
\end{tabular}

\begin{tabular}{|c|c|c|c|}
\hline $\begin{array}{l}\mathrm{OA} \\
(\mathrm{We}\end{array}$ & $\begin{array}{l}\mathrm{SON} \\
\mathrm{k})\end{array}$ & $\begin{array}{c}0.700 \\
0\end{array}$ & $\begin{array}{c}3.956 \\
5\end{array}$ \\
\hline $\begin{array}{l}\text { OA } \\
\text { (Str }\end{array}$ & $\begin{array}{l}\text { SON } \\
\text { ng) }\end{array}$ & $\begin{array}{c}1.700 \\
0\end{array}$ & $\begin{array}{c}3.956 \\
5\end{array}$ \\
\hline$O A$ & CAM & $\begin{array}{c}0.375 \\
0\end{array}$ & $\begin{array}{c}4.256 \\
5\end{array}$ \\
\hline$O A$ & $\mathrm{CM}$ & $\begin{array}{c}0.365 \\
0\end{array}$ & $\begin{array}{c}3.987 \\
0\end{array}$ \\
\hline $\mathrm{OA}$ & $\mathrm{CT}$ & $\begin{array}{c}0.437 \\
2\end{array}$ & $\begin{array}{c}4.033 \\
0\end{array}$ \\
\hline $\begin{array}{l}\mathrm{SON} \\
(\mathrm{We}\end{array}$ & $\begin{array}{l}\mathrm{SON} \\
\mathrm{k})\end{array}$ & $\begin{array}{c}0.650 \\
0\end{array}$ & $\begin{array}{c}4.450 \\
0\end{array}$ \\
\hline $\begin{array}{l}\text { SON } \\
\text { (Str }\end{array}$ & $\begin{array}{l}\text { SON } \\
n g)\end{array}$ & $\begin{array}{c}1.750 \\
0\end{array}$ & $\begin{array}{c}4.450 \\
0\end{array}$ \\
\hline $\mathrm{SON}$ & CAM & $\begin{array}{c}0.360 \\
6\end{array}$ & $\begin{array}{c}4.050 \\
0\end{array}$ \\
\hline $\mathrm{SON}$ & $\mathrm{CM}$ & $\begin{array}{c}0.236 \\
5\end{array}$ & $\begin{array}{c}3.930 \\
0\end{array}$ \\
\hline $\mathrm{SON}$ & $\mathrm{CT}$ & $\begin{array}{c}0.243 \\
7\end{array}$ & $\begin{array}{c}3.942 \\
5\end{array}$ \\
\hline CAM & CAM & $\begin{array}{c}0.200 \\
0\end{array}$ & $\begin{array}{c}4.800 \\
0\end{array}$ \\
\hline CAM & $\mathrm{CM}$ & $\begin{array}{c}0.295 \\
0\end{array}$ & $\begin{array}{c}4.650 \\
0\end{array}$ \\
\hline CAM & $\mathrm{CT}$ & $\begin{array}{c}0.295 \\
0\end{array}$ & $\begin{array}{c}4.650 \\
0\end{array}$ \\
\hline $\mathrm{CM}$ & $\mathrm{CM}$ & $\begin{array}{c}0.420 \\
0\end{array}$ & $\begin{array}{c}4.506 \\
0\end{array}$ \\
\hline $\mathrm{CM}$ & $\mathrm{CT}$ & $\begin{array}{c}0.444 \\
0\end{array}$ & $\begin{array}{c}4.545 \\
5\end{array}$ \\
\hline
\end{tabular}




\begin{tabular}{|ll|l|l|}
\hline CT CT & 0.469 & 4.585 \\
\hline
\end{tabular}

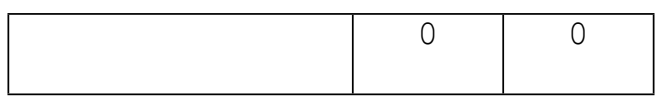

(1) https://www.SPICA-FF.org/.

(2) Shinoda, W.; DeVane, R.; Klein, M. L. Coarse-Grained Molecular Modeling of Non-Ionic Surfactant Self-Assembly. Soft Matter 2008, 4 (12), 2454. https://doi.org/10.1039/b808701f. 